\title{
Ensuring Quality through Stakeholder Engagement: Syllabus Revision at Aga Khan University Examination Board
}

\author{
Raabia Hirani, Naveed Yousuf, Shehzad Jeeva \\ Aga Khan University - Examination Board \\ Pakistan
}

\begin{abstract}
Pakistan's first private autonomous national examination body for secondary (SSC) and higher secondary (HSSC) school certifications, Aga Khan University Examination Board (AKU-EB), revised its syllabus review and revision process in 2015-16. It has recently completed one cycle of syllabus revision using this new process. One of the key features of the revised process is the greater engagement of all the identified key stakeholders at different stages of the review process. The stakeholders include students, teachers, content and examination specialists, teacher trainers and university faculty. The objective, mode and level of engagement of each stakeholder differed depending on their stake in the syllabus and their expertise. Current literature on engagement of stakeholders in curriculum revision emphasizes its importance for maintenance of quality, particularly according to the Total Quality Management (TQM) model of education and curriculum development. However, such engagement has often proved difficult, especially on the national level. The paper discusses the method which has recently been successfully used to engage diverse stakeholders in the syllabus review at the national level. Furthermore, it discusses how this process meets the requirements of TQM. It also discusses the benefits, challenges and impact of this process.
\end{abstract}

\section{Introduction}

In education, the term 'quality' is frequently used to mean the highest possible standard that cannot be surpassed. This concept, however, is elitist and unrealistic [1].

Broadly and more realistically, quality can be explained in terms of compliance with two aspects: (a) the ability to meet expectations and (b) commitment to and potential for continuous improvement [1][2].

Total Quality Management (TQM) is most frequently applied to educational processes and institutions to ensure quality [3]. This model has six basic principles [4]:

1. Leadership - committed to quality

2. Customers - focus on customer satisfaction and delight

3. Employees - involvement of all

4. Suppliers - maintaining true relations
5. Continuous quality improvement - ongoing incremental steps towards quality

6. Performance measures - management by fact

While this paper discusses the syllabus revision process at the Aga Khan University Examination Board (AKU-EB), it also highlights how the principles of TQM model facilitated to focus on the needs of the stakeholders and to effectively engage them in the process.

\section{Context}

Aga Khan University Examination Board (AKUEB) is Pakistan's first private national autonomous examination body for secondary (SSC) and higher secondary (HSSC) school certifications which conducts examinations across the country. In Pakistan, SSC comprises of grades IX and X and HSSC comprises of grades XI and XII. High stakes examinations are conducted at the end of all four grades. After grade XII, majority of AKU-EB students move towards university education; some move towards certifications like ACCA (Association of Chartered Certified Accountants Qualification) and only a small minority discontinues education, mostly to join the job market.

AKU-EB was established in 2002 with aims to increase access to quality education, particularly among middle and lower income group students. While following the benchmarks of the National Curriculum of Pakistan, it inculcates a culture of conceptual and higher-order thinking in students while countering the culture of rote-learning.

AKU-EB develops syllabi based on the National Curriculum, provides support to schools in the form of teacher development and teaching and learning resources and conducts examinations based on the syllabi across the country. For administration and efficiency, AKU-EB operationally categorizes the expanse of the country into three main regions, expanding from mountainous rural north to coastal urban south, each with its own needs, strengths and challenges. Hence, AKU-EB works on an integrated model which aligns syllabi, teaching, learning and assessment for its affiliated schools across the country. This is achieved through the collaborative 
work of its teams, i.e. Curriculum Development, Examination Development, Assessment, Teacher Development, Operations and Communications. AKU-EB maintains good communication with its affiliated schools primarily through annual events, meetings and teacher training workshops.

Until 2014, AKU-EB was in its developing phase where it established itself as a pioneer of fair, reliable and valid assessment in Pakistan while working to overcome the culture of rote-learning and cheating in examinations.

In 2015, having broken the initial inertia of apathy towards education and assessment in the country, AKU-EB aimed even higher with new leadership.

With its new aim to be a model of excellence and innovation in education for Pakistan and the developing world, AKU-EB took many initiatives.

\subsection{Aims of Syllabus Revision}

One of AKU-EB's new initiatives was revising the aims of its syllabi and syllabus revision process in light of its previous achievements, international new trends in curriculum development, and the changing needs of its immediate context so that it can remain up-to-date and relevant.

The new aims are to:

1. review the learning objectives for inclusion of new knowledge and deletion of obsolete knowledge

2. review the content for clarity and relevance as per the changing needs of students, teachers and society

3. ensure development of higher-order thinking and problem solving skills in students

4. enhance and strengthen continuation and progression of content both within and across grades IX - XII (SCC and HSSC)

5. ensure the readiness of students for higher education

6. ensure the needs of the direct and indirect stakeholders are identified and addressed

7. ensure continued compatibility with the goals of National Curriculum of Pakistan

In order to achieve these aims, a systematic, methodical and innovative syllabus revision method was designed.

The syllabus revision cycle has been made an annual activity and it is repeated every year for a different set of subjects. Hence, SSC and HSSC syllabi of a total of 40 subjects are expected to be revised in 4 years, after which, the process will be repeated resulting in each syllabus being reviewed and revised after every four years. By now, AKU-EB has successfully completed one syllabus revision cycle and is almost half way through its second syllabus revision cycle.
One of the new features of this revised, more thorough process is that it engages multiple stakeholders including students, teachers, content and examination specialists, university faculty and teacher trainers at different stages, each having a distinctive objective, mode and level of engagement.

\subsection{Aims of this Paper}

This paper aims to discuss the syllabus revision process specifically identification of stakeholders and reasons for such, methods and tools used to engage the stakeholders as well as the successes and challenges. It seeks to demonstrate that engagement of stakeholders in indeed possible if the method acknowledges and addresses the local needs and challenges and the institution which uses the method maintains good ties with the stakeholders over the years. Hence, it demonstrates how to follow these procedures of stakeholder engagement to satisfy the key principles of Total Quality Management (TQM).

\section{Literature Review}

International and regional practices in curriculum development from several countries ranging from United States, Britain [5] and Australia [6] to Pakistan and India show that curriculum development at the national and state levels is dominated by specialists like academics, professional consultants and officials with experience in curriculum development while teachers are only involved at the district, school and classroom level [7]. The importance of involving diverse stakeholders is widely acknowledged [8]. However, their involvement has mostly been reported for curricula of schools and universities [9]. Evidence of a national institution or body sharing such practices for others to learn has not been found. The need for engaging stakeholders has been discussed extensively by $M$. Bezzina et al with reference to the national curriculum development in Australia [10] and a multistakeholder-driven model for excellence in higher education curriculum development has been proposed for South Africa by M. H. Meyer and M. J. Bushney. However, the proposed method has not yet been tested [11].

Despite the identified need and proposed methods, the engagement of different stakeholders in syllabus revision, such implementation has not been seen in the literature. The reason often cited for this being a challenging task is that the magnanimous feat of involving an adequate number of diverse stakeholders is difficult due to constraints of time and resources [11]. Hence, often, no students [13] and only a limited number of teachers are involved in the process and these participants are expected to be mediators for students and the rest of the teachers [12]. 
In the literature regarding the role of Total Quality Management (TQM) in educational activities in general, and syllabus or curriculum revision in particular, the role of customers has been regarded as crucial but challenging [1] [3]. It is quite possible for customers to reject perfectly suitable products and models [1] due to the difference between their longterm needs and short-term desires [3]. Hence, while it cannot be denied that it is very important to engage them and satisfy their needs, it is even more important to ensure that the process does not sacrifice these needs in favour of short-term desires. For example, students are likely to have the short-term desire for the syllabus to be easy so that they can score A grade and teachers can have the short-term desire for the syllabus to be shorter so that they can cover it easily. However, the syllabus revision process should facilitate in finding out and addressing their actual need as opposed to these short-term desires.

\section{Identification and Engagement of Stakeholders}

In the syllabus review process of AKU-EB, effective engagement of multiple stakeholders has been ensured by first identifying the following:

a) Who are the stakeholders?

b) What is at stake for them?

c) What will their contribution bring to the revised syllabus?

d) What is the best method to engage them considering their required contribution and the limitations of time and resources?

\subsection{Stake and Contribution}

The stakeholders were identified considering the impact of the syllabus revision on them, their expertise, experience and role in syllabus implementation which can be used to contribute to the syllabus [14]. In terms of TQM principles, these stakeholders include both, the customers as well as the employees.

The direct and most important stakeholders of the syllabus were identified to be the students who will be expected to achieve the outcomes of the syllabus and will assessed on them.

After them in priority are those stakeholders who are expected to help the students to achieve the outcomes, i.e. their teachers, and those that will assess the achievement of outcomes of the syllabus, i.e. exam item developers and assessment experts. Both the teachers and exam developers are expected to be subject matter experts (SMEs).

In addition to these are the indirect stakeholders. These include the teacher trainers who are expected to train these teachers; principals and head-teachers who are school leaders; teachers of the previous grade who ensure that the students are prepared for their current grade; teachers of the next grade who are aware of the skills and knowledge which would be required for the next level of education; and finally university faculty who are responsible for students' guiding development beyond HSSC and are the gatekeepers of professions.

Teachers from schools not affiliated with AKUEB had also been included for diversity, inclusion and new thoughts. Where needed, government personnel have also been approached and official documents produced by university admission committees and government bodies have been referred to ensure that expected benchmarks are achieved.

The entire process was led by curriculum development experts.

\subsection{Methods of Engagement}

The syllabus revision process can be divided into three stages:
a) Needs Assessment and Feedback
b) Design and Content Revision
c) Dissemination

The continuum of these stages, sub-stages and relative involvement of stakeholders in each stage is shown in Table 2.

4.2.1. Needs Assessment. AKU-EB's syllabus review process started with targeted needs assessment of students and teachers of affiliated schools using a specific questionnaire for each. A combination of questioning techniques were used including openended questions and questions asking for relative importance and efficiency of different factors using Likert scales.

Table 2. Stages of syllabus revision corresponding to the involvement of stakeholders

\begin{tabular}{|c|c|c|}
\hline Sub-Stages & Methods & Stakeholders \\
\hline \multicolumn{3}{|c|}{ Stage 1: Needs Assessment and Feedback } \\
\hline $\begin{array}{c}\text { Needs } \\
\text { Assessment }\end{array}$ & $\begin{array}{c}\text { Survey } \\
\text { questionnaires } \\
\text { Interviews } \\
\text { Written } \\
\text { feedback }\end{array}$ & $\begin{array}{c}\text { Teachers and } \\
\text { students who are } \\
\text { studying/ teaching } \\
\text { the syllabus } \\
\text { (equal } \\
\text { representation from } \\
\text { high, middle and } \\
\text { low achieving } \\
\text { schools from across } \\
\text { the country was } \\
\text { ensured) } \\
\text { Exam item } \\
\text { developers }\end{array}$ \\
\hline Sta & Design and C & nt Revision \\
\hline
\end{tabular}




\begin{tabular}{|c|c|c|}
\hline $\begin{array}{l}\text { Panel } \\
\text { Review }\end{array}$ & $\begin{array}{l}\text { Structured } \\
\text { Discussions } \\
\text { Consensus } \\
\text { Building } \\
\text { Exercises } \\
\\
\text { Syllabus } \\
\text { Writing }\end{array}$ & $\begin{array}{l}\text { Teachers who are } \\
\text { teaching the grade } \\
\text { Teachers who are } \\
\text { teaching one grade } \\
\text { below } \\
\text { Teachers who are } \\
\text { teaching one grade } \\
\text { above }\end{array}$ \\
\hline $\begin{array}{l}\text { Teacher } \\
\text { Trainers' } \\
\text { Review }\end{array}$ & $\begin{array}{c}\text { Independent } \\
\text { written and } \\
\text { verbal feedback } \\
\text { on the syllabus } \\
\text { and } \\
\text { corresponding } \\
\text { teacher-support } \\
\text { material }\end{array}$ & Teacher trainers \\
\hline $\begin{array}{c}\text { University } \\
\text { Preparedness } \\
\text { Review }\end{array}$ & $\begin{array}{c}\text { Independent } \\
\text { Reviews } \\
\text { through: } \\
\text { Questionnaires } \\
\text { Interviews }\end{array}$ & $\begin{array}{l}\text { University faculty } \\
\text { (preferably those } \\
\text { who teach first year } \\
\text { undergraduate) }\end{array}$ \\
\hline \multicolumn{3}{|c|}{ Stage 3: Dissemination } \\
\hline $\begin{array}{l}\text { Principals' } \\
\text { Focus } \\
\text { Groups }\end{array}$ & $\begin{array}{l}\text { Meetings with } \\
\text { focus group of } \\
\text { each region }\end{array}$ & $\begin{array}{c}\text { Selected principals } \\
\text { of affiliated schools } \\
\text { (equal } \\
\text { representation from } \\
\text { high, low and } \\
\text { middle achieving } \\
\text { schools was } \\
\text { ensured; meeting } \\
\text { were held in } 2 \\
\text { regions and on } \\
\text { video conferencing } \\
\text { for other regions) }\end{array}$ \\
\hline $\begin{array}{c}\text { Training } \\
\text { Needs } \\
\text { Assessment }\end{array}$ & $\begin{array}{c}\text { Written } \\
\text { feedback } \\
\text { Telephonic } \\
\text { interviews }\end{array}$ & $\begin{array}{c}\text { Teachers and } \\
\text { students who are } \\
\text { studying/ teaching } \\
\text { the syllabus }\end{array}$ \\
\hline
\end{tabular}

The survey was shared with all the AKU-EB affiliated schools via email, website and post, and follow up calls were made to encourage both teachers and students to respond. A total of 248 students and 276 teachers from SSC and HSSC participated in this survey from across Pakistan. The purpose of this survey was to identify the sections of the syllabus which (a) are problematic and need to be modified (b) are difficult to teach and learn and hence need better learning resources (c) inculcate higher order thinking in students and hence need to be retained and enhanced. Interviews and group meetings were also conducted where needed. Needs assessment of exam item developers was also done through written feedback on the syllabus.

The results of the needs assessment were shared with the curriculum development team, who used the data to make over-arching structural changes to the syllabus by modifying or removing the aspects which were not useful and adding those that where needed to further enhance the syllabus. For example, the list of command words was removed from individual syllabus documents and a separate command word guide was developed. In addition, concept maps were added with each syllabus document.

The subject-specific findings of the results were also categorised and were then shared with the relevant subjects' syllabus review panel.

4.2.2. Panel Review. Needs assessment was followed by subject-wise panel reviews. Each subject panel, comprising primarily of subject matter experts (SMEs), thoroughly reviewed the SSC and HSSC syllabi for their respective subjects.

The panel included 2-3 teachers of the same grade, of whom at-least one was from a non-AKU-EB affiliated school; at least one teacher from a grade above and one from the grade below; one university faculty from a field most relevant to the subject; AKU-EB's content specialists, exam item developers and assessment experts.

Feedback from teachers and students that was collected during needs assessment was shared with each group. This group followed a 4-step process of syllabus revision, i.e. (a) benchmarking using the National Curriculum and other curricula and revision of progression (b) writing and revision of student learning outcomes accordingly to the revised progression (c) compilation and development of learning resources according to the new student learning outcomes (d) development of exam specification for the revised syllabus.

In the first cycle of syllabus revision it was observed that teachers and subject matter experts (SMEs) do not always possess curriculum development expertise and hence struggle with the tasks assigned to them during panel review. Hence, in second syllabus revision cycle, which is currently in process, a one-day training and hands-on practice session was arranged for the panelists prior to the panel review.

4.2.3. Teacher Trainers' Review. Due to the nature of their job, teacher trainers are often in the field. They are not able to provide the kind of time commitment required for being part of a panel. Hence, they were engaged separately. Most of them are SMEs as well.

The teacher training team of AKU-EB reviewed the revised syllabus and learning resource lists in their own time to ensure that adequate resources have been identified and/or developed to ensure that the teachers have the required support needed to implement the 
syllabus. During their review, they also identified the areas in which training will have to be conducted to ensure smooth implementation of the syllabus.

4.2.4. University Preparedness Review. The university preparedness review engaged the university faculty who are also important stakeholders of the AKU-EB syllabus. Their review ensured university readiness of the students who study the syllabi. They reviewed the syllabus for relevance, coverage and relative weightage of content and skills with reference to the requirements of undergraduate programs. The reviewers were selected from universities identified in the annual university destination survey conducted by AKU-EB for its graduating students and academic repute.

For subjects like Accounting in which students are more likely to progress towards professional chartered accountancy certifications like ACCA, faculty of the certificate awarding bodies were engaged in the review.

4.2.5. Principals' Focus Group. Once the syllabi were finalised, focus groups of principals were made from all four regions in which AKU-EB has affiliated schools. Adequate representation was ensured from all sub-regions, socio-economic groups and achievement quartiles. The changes in the syllabus, rationale for the changes, and newly developed teaching and learning resources were shared with them. Their feedback was taken regarding any additional support that may be needed and they were entrusted with encouraging their teachers to review the revised syllabi and share their training needs with AKU-EB within an assigned time.

4.2.6. Training Needs Assessment. This step has recently started since the revised syllabi have been shared with schools. This is an on-going process in which the training needs of teachers and students of each region will be analysed and trainings and teaching and learning resources will be developed and shared accordingly. Teachers and students of AKUEB already have a culture of sharing their needs with the examination board via emails. They are further being encouraged via phone calls and discussions during AKU-EB's on-going events and trainings.

\section{Quality Management}

The process of syllabus revision described here follows many of the principles of TQM including leadership's commitment to quality; customer satisfaction; effective engagement of employees; maintaining true relationships with suppliers and continuous quality improvement and measurement of performance through facts.

\subsection{Leaderships' Commitment to Quality}

AKU-EB's leadership's commitment to quality is apparent in the revamping of the syllabus revision process with aims which are thorough, forwardlooking and commitment to stakeholders' needs and expectations. Commitment was necessary to design, develop and implement the syllabus revision process and lead the team through it. It is also apparent in the willingness to make changes where needed.

\subsection{Customer Satisfaction}

There are two distinct types of customers external and internal [2]. For AKU-EB, the internal customers include the staff, i.e. the subject matter experts (SMEs), exam item writers, assessment experts and teacher trainers while the external customers include teachers, students and principals of AKU-EB affiliated schools.

The satisfaction of the teachers, students and principles has been achieved by engaging them in the process and ensuring that their needs, rather than their short-term wishes have been catered to. This was ensured through including members of high, low and middle achieving schools to ensure that everyone's needs are identified and addressed.

Since the syllabus is yet to be implemented, quantitatively, only the principal's satisfaction has been measured during the principals' focus group meeting in which $92.9 \%$ of the participants affirmed that the syllabus is useful or very useful for them.

Data on teacher and student feedback is expected once the syllabi are implemented in the classroom.

\subsection{Engagement of Employees}

Employee engagement was ensured by bringing flexibility to the syllabus revision process. An example of this is the engagement of members of the teacher development team who are busy in training and capacity development work throughout the country. Despite this, their feedback and engaged was ensured in the process such that it did not clash with their regular engagements.

\subsection{Maintaining True Relationships with Suppliers}

AKU-EB syllabi are based on the National Curriculum of Pakistan. Hence, it is important for the syllabi to be aligned to this curriculum. Hence, it would be apt to consider the National Curriculum Wing, which developed the National Curriculum, as the supplied in this model.

In order to maintain good relationships with this government organization, their representatives were taken into confidence at the start of the process. 
Moreover, their feedback was also taken on politically sensitive subjects like Pakistan Studies.

\subsection{Continuous Quality Improvement}

This is apparent not only from the initial initiative to reform the syllabus revision process but also from the commitment to keep improving it. For example, the training of syllabus revision panelists was added to the second cycle of syllabus revision to ensure that they can fulfill their duties efficiently.

\subsection{Performance Measures}

Performance measures refer to management by facts and not assumptions. This was ensured from the beginning of the process, where the expectations and needs of the students and teachers were clearly identified during needs assessment survey, were addressed by multiple reviews and finally verification through the university preparedness review in which the efficiency of the syllabus in preparing students for university education was confirmed. Further verification, identification of areas of improvement and hence improvement in the process and the syllabi are expected during syllabus implementation.

\section{Discussion}

Effective stakeholder engagement has indeed been found to be an effective tool for ensuring the quality of the syllabus revision process at AKU-EB. The implementation of the six core principles of TQM has been made possible by commitment to and methods for the engagement of multiple stakeholders.

The complete impact of this process in increasing the satisfaction and motivation of the stakeholders has not been studied formally but the revision process's alignment with the TQM principles is encouraging.

Having said that, the responses received so far from the external customers, i.e. teachers, students and principals, have been encouraging. For example, one principal commented, "What is wonderful about AKU-EB is that they listen to us and address our queries and concerns".

This process of engaging stakeholders directly meets the second aim of the syllabus revision. However, other aims (as discussed in the introduction) have also indirectly been met as a result of this. One such impact is that the number of student learning outcomes which address higher order skills has increased by $10 \%$ which addresses the aim of developing higher-order thinking in students.

Moreover, higher education preparedness of students through the syllabus has been confirmed in the higher education preparedness review in which $100 \%$ of reviewers affirmed that the syllabi's content mostly or completely prepare students for higher education and $92.9 \%$ of the principals' focus group participants affirmed that the syllabus is useful or very useful for them.

\section{Conclusion}

The process of engaging multiple categories of stakeholders, often a large number of them, has been both satisfying and challenging. Its alignment with the $\mathrm{TQM}$ principles in encouraging.

Since this process has already been carried out, it goes to show that it is indeed a practical and implementable method of engaging stakeholders for a national-level syllabus which can be replicated.

It required a holistic approach and an integrated model of educational institution. An educational institution that aim to engage its stakeholders should have diverse expertise, good on-going relationships with relevant stakeholders to ensure their cooperation, and effective use of resources and communication tools to ensure cost-effectiveness.

\section{Acknowledgements}

The authors of this paper acknowledge the dedication and hard work of all those who were involved in this process, including, Banazeer Yaqoob, Associate Curriculum Development, and the entire Curriculum and Examination Development, Assessment and Teacher Development teams as well as Operations and Communications teams of AKU-EB for their support.

\section{References}

[1] Sallis, E. Total Quality Management in Education (3rd ed.), 2002, London: Kogan Page Ltd.

[2] D.H. Besterfield, C. B.-M.-S. Total Quality Management (3 ed.), 2002, Delhi: Pearson.

[3] R.C. Winn, R.S. Green (1998). "Applying Total Quality Management to the Educational Process" International Journal of Engineering Education, 1998, pp. 24-28.

[4] Yousuf, N. "Total Quality Management: Do Health Profession Educators Need to be Educated?" Education in Medicine Journal, 3(2), 2011, pp. 65-69.

[5] G. Bielby, M. Judkins, L. O’Donnell and T. McCrone, "Review of the Curriculum and Qualification Needs of Young People who are at Risk of Disengagement", NFER Research Programme: From Education to Employment, 2012, Slough: NFER.

[6] "Review of the Australian Curriculum Final Report", Department of Education, Australian Government, 2014

[7] C.J. Marsh and G. Willis, Curriculum: Alternative Approaches, Ongoing Issues, Pearson Education Inc., New Baskerville, 2007, pp. 159-160. 
[8] J.N. Wood, "Engaging Stakeholders in Curriculum Development", Journal of School Public Relations, 2010, Vol. 31 Spring, pp. 122-129.

[9] S. L. Oliver and E. Hyun "Comprehensive curriculum reform in higher education: collaborative engagement of faculty and administrators"

[10] M. Bezzina, R. J. Starratt, C. Burford, "Pragmatics, Politics and Moral Purpose: The Quest for an Authentic National Curriculum", Journal of Educational Administration, 2009, Vol. 47 Iss: 5, pp. 545-556.

[11] M.H. Meyer, and M.J. Bushney, "Towards a MultiStakeholder-Driven Model for Excellence in Higher Education Curriculum Development." South African Journal of Higher Education, 2008, Vol. 22, no. 6: pp. $1229-1240$

[12] A. Buckley, "UK Engagement Survey: Students' Perceptions of Skills Development", Higher Education Academy, 2015, pp. 27.

[13] M.A. Alsubaie, "Curriculum Development: Teacher Involvement in Curriculum Development", Journal of Education and Practice, 2016, Vol. 7, pp. 106.

[14] M.H. Meyer, and M.J. Bushney, "Towards a MultiStakeholder-Driven Model for Excellence in Higher Education Curriculum Development." South African Journal of Higher Education, 2008, Vol. 22, no. 6: pp. $1235-1236$ 